\title{
LITERATURE REVIEW : HUBUNGAN KOORDINASI TERHADAP KETERAMPILAN MENENDANG BOLA PADA PEMAIN SEPAK BOLA
}

\author{
Eka Fitri Haryanti ${ }^{1}$, Agustiyawan ${ }^{2 *}$, Purnamadyawati ${ }^{3}$, Hanidar ${ }^{4}$ \\ ${ }^{1,2,3}$ Program Studi Fisioterapi Program Diploma Tiga, Fakultas Ilmu Kesehatan \\ Universitas Pembangunan Nasional Veteran Jakarta, Indonesia \\ ${ }^{4}$ Fisioterapis RSPAD Gatot Soebroto, Indonesia \\ *Email : agustiyawan@upnvj.ac.id
}

\begin{abstract}
ABSTRAK
Menendang bola merupakan teknik dasar yang penting dalam permainan sepak bola yang salah satu tujuannya yaitu menembak bola ke gawang lawan (shooting). Kemampuan menendang bola yang baik, berkaitan dengan koordinasi, karena koordinasi berfungsi untuk mengarahkan bola secara tepat dan akurat saat melakukan tendangan. Tujuan literature review ini adalah untuk menganalisa serta menelaah penelitian yang telah dilakukan sebelumnya mengenai hubungan koordinasi terhadap keterampilan menendang bola pada pemain sepak bola. Metode yang digunakan pada literature review ini yaitu metode traditional literature review, yang merupakan analisis secara komprehensif, kritis, dan objektif terkait dengan ilmu atau pengetahuan mengenai topik tertentu yang tidak memiliki metode khusus dalam strategi pencarian pustaka. 5 dari 6 artikel yang direview oleh penulis menunjukkan hasil bahwa terdapat hubungan koordinasi terhadap keterampilan menendang bola pada pemain sepak bola. Hal ini disimpulkan berdasarkan hasil artikel yang telah direview oleh penulis dan berdasarkan penilaian kualitas artikel yang dinilai melalui Scimago Journal \& Country Rank (SJR) yang memiliki nilai Q4, Sinta (Science and Technology Index) yang memiliki nilai S3 dan S4, dan critical appraisal yang mendapatkan hasil dengan nilai kategori A (high) dan B (limited) dalam levels of internal validity.
\end{abstract}

Kata Kunci: koordinasi, menembak, menendang bola, sepak bola

\begin{abstract}
Kicking a ball is an important basic technique in a soccer game where one releases a shot at the opponent's goal (shooting). Good game in kicking the ball, related to coordination. Coordination serves to direct the ball precisely and accurately when making a kick. The purpose of this literature review is to analyze and examine previous research conducted on studies of the correlation to soccer kicking skills in soccer players. The method used in this literature review is the traditional literature review method, which is a complete, critical, and objective analysis related to the knowledge or knowledge of a particular topic that does not have a specific method in the library search strategy. 5 of the 6 articles reviewed by the author show the results about the contribution to soccer kicking skills in soccer players. This was concluded based on articles that have been reviewed by the author and on the assessment of the quality of articles issued through the Scimago Journal \& State Ranking (SJR) with results showing Q4, Sinta (Science and Technology Index) with results showing S3 and S4 values, and critical appraisal which gets results with category A (high) and B (limited) values in levels of internal validity.
\end{abstract}

Keywords: coordination, shooting, kicking, soccer 


\section{PENDAHULUAN}

Olahraga paling disukai didunia salah satunya ialah sepak bola. Olahraga ini sangat mudah dinikmati untuk semua generasi, mulai dari anak-anak sampai dewasa, apalagi di segala tempat seperti di jalan, sekolah, ataupun taman bermain, serta untuk para pemain sepak bola professional di kompetisi sekelas piala dunia (Andualem. G., Silassie, \& Demena, 2016). Tujuan permainan sepak bola ialah menjaga gawang sendiri agar bola tidak masuk dan untuk memasukkan bola sebanyaknya ke gawang musuh, dalam meraih tujuan tersebut maka diperlukan kebugaran fisik dan penguasaan teknik dasar yang bagus.

Menendang bola ialah teknik dasar penting dalam bermain sepak bola. Tujuannya untuk memberikan operan, menembakkan banyak bola ke gawang musuh, untuk mematahkan serangan musuh, tendangan sudut, tendangan gawang, dan tendangan bebas (Ardiansyah, 2018). Kemampuan menendang bola dengan baik, berkaitan dengan koordinasi, karena tanpa adanya koordinasi maka akan sulit untuk mengarahkan bola secara tepat saat melakukan tendangan. Dengan demikian, fungsi koordinasi yaitu menghasilkan suatu gerakan yang tepat, cepat, dan efisien (Anam, Irawan and Nurrachmad, 2018).

Penelitian menurut (Adityatama, 2017) mengatakan bahwa koordinasi memiliki hubungan terhadap keterampilan menendang bola. Namun ada juga penelitian yang mengatakan bahwa koordinasi tidak memiliki hubungan terhadap keterampilan menendang bola (Andualem. G., Silassie, \& Demena, 2016). Maka dari itu, perlu analisis lebih lanjut untuk membuktikan apakah terdapat hubungan koordinasi terhadap keterampilan menendang bola. Hal tersebut dapat dilakukan oleh seseorang yang memahami gerak dan fungsi yang berkaitan dengan koordinasi serta olahraga sepak bola, salah satunya yaitu fisioterapis.

Fisioterapis dapat memperhatikan komponen kebugaran fisik pemain sepak bola agar lebih memaksimalkan kemampuannya dalam meningkatkan teknik dasar yang digunakan, khususnya teknik menendang bola.
Untuk memaksimalkan kemampuan teknik menendang bola, maka diperlukan koordinasi agar tendangan bola tepat sasaran, sehingga tujuan permainan sepak bola dapat teraih.

Oleh karena itu penulis tertarik untuk melakukan literature review mengenai hubungan koordinasi terhadap keterampilan menendang bola pada pemain sepak bola.

\section{METODE}

Penulis melakukan literature review dengan menggunakan metode traditional literature review. Traditional literature review merupakan analisis yang komprehensif, kritis, dan objektif terkait ilmu atau pengetahuan mengenai topik tertentu yang tidak memiliki pertanyaan penelitian yang spesifik atau metode khusus dalam strategi pencarian pustaka.

Pada literature review ini penulis menganalisis tentang hubungan koordinasi terhadap keterampilan menendang bola pada pemain sepak bola. Variabel yang digunakan ialah koordinasi dan menendang bola. Populasinya yaitu seluruh sumber kepustakaan yang berkaitan dengan topik literature review ini. Sedangkan sampelnya ialah seluruh sumber penelitian dengan topik hubungan koordinasi terhadap keterampilan menendang bola pada pemain sepak bola yang memenuhi kriteria inklusi.

Adapun kriteria inklusi pada literature review ini yaitu artikel yang mempunyai judul dan isi yang relevan dengan tujuan penulisan, artikel penelitian yang terpublikasi secara nasional atau internasional, artikel penelitian yang dipublikasikan pada tahun 2012-2020, artikel penelitian yang full text, artikel penelitian yang terindeks Scimago Journal and Country Rank (SJR) dan Sinta (Science and Technology Index), dan artikel penelitian yang memiliki nilai levels of internal validity minimal kategori B (limited) menurut critical appraisal.

Strategi penelusuran literature review yakni dengan menganalisis atau membuat ringkasan dari beberapa artikel atau jurnal penelitian yang berkaitan dengan pertanyaan dan tujuan penulisan. Pencarian literatur (searching literature) adalah proses pencarian 
mendalam terhadap informasi terpublikasi tentang suatu topik. Pencarian literatur bertujuan untuk mendapatkan publikasi ilmiah terhadap suatu topik dengan sebanyakbanyaknya.

Metode pencarian untuk sumber data literature review ini diperoleh dari studi pustaka yang telah dipublikasikan melalui database elektronik diantaranya adalah Google Scholar, Garba Rujukan Digital, Science Direct, PubMed, dan berbagai situs jurnal lainnya serta buku-buku dan data tertulis lainnya yang berkaitan dengan judul penulisan ini. Kata kunci yang dipakai dalam pencarian literatur ini yaitu : "koordinasi dan shooting", "koordinasi dan menendang bola", "hubungan koordinasi dan menendang bola", "hubungan koordinasi mata kaki terhadap shooting bola". Sumber literatur yang digunakan merupakan literatur yang diterbitkan 8 tahun terakhir yaitu 2012-2020 dan diseleksi menggunakan kriteria inklusi.

\section{PEMBAHASAN}

Penulis melakukan literature review terhadap enam literatur berupa jurnal penelitian yang telah terpublikasi dan berkaitan dengan judul penulisan. Artikel tersebut ditemukan pada database elektronik Google Schoolar dan Garba Rujukan Digital.

Artikel pertama yang dijadikan sebagai sumber literatur utama oleh penulis yaitu penelitian "A Study of Agility, Coordination and Speed as Related to Dribbling and Kicking Performance of Jimma, Woliso and Sebeta Town Male Football Players" yang dipublikasikan oleh Journal of Physical Education Research, Volume 3, Issue I, March 2016 dan ditulis oleh Andualem. G., Silassie, \& Demena. Penelitian ini memiliki nilai Q4 menurut Scimago Journal \& Country Rank (SJR) dan memiliki nilai levels of internal validity dengan kategori A (high) menurut metode critical appraisal. Metode penelitiannya ialah desain cross sectional. Penelitian dilakukan terhadap 52 sampel yang merupakan pemain sepak bola laki-laki klub Jimma, Woliso dan Sebeta yang dipilih secara acak untuk mengetahui hubungan koordinasi dengan menendang bola. Sebelum sampel melakukan pengukuran pada variabel yang akan diteliti, sampel melakukan pengisian Physical Activity Readiness Questionnaire (PAR-Q). Formed pass for accuracy dilakukan untuk mengukur keterampilan menendang bola dimana pemain menendang bola secara akurat, sedangkan eye-leg coordination test dilakukan untuk mengukur koordinasi. Hasil uji statistik korelasi yang didapatkan pada penelitian ini mengenai variabel koordinasi dan menendang bola adalah $r=-0,06$, dimana $p>0,05$. Sehingga penelitian ini menyatakan bahwa menendang bola tidak memiliki hubungan dengan koordinasi. Hal ini dikarenakan kebugaran fisik yang digunakan merupakan gabungan dari faktor terkait kelincahan, koordinasi dan kecepatan. Oleh karena itu, dilakukan penelitian lagi secara terpisah baik dari faktor kelincahan, koordinasi dan kecepatan supaya membuktikan analisis yang lebih kuat lagi terkait adanya hubungan koordinasi terhadap keterampilan menendang bola (Andualem. G., Silassie, \& Demena, 2016).

Artikel kedua yang ditemukan oleh penulis yaitu penelitian "Hubungan Power Otot Tungkai, Koordinasi Mata Kaki dan Kekuatan Otot Perut dengan Ketepatan Menembak Bola” yang dipublikasikan oleh JUARA: Jurnal Olahraga Volume 2, Nomor 2, 2017 dan ditulis oleh Adityatama. Penelitian ini memiliki nilai S3 menurut Sinta (Science and Technology Index) dan memiliki nilai levels of internal validity dengan kategori B (limited) menurut metode critical appraisal. Penelitian ini merupakan penelitian deskritiptif korelasional dan salah satu tujuannya yaitu untuk mengetahui hubungan koordinasi mata kaki dengan ketepatan menembak bola ke gawang sepak bola pada pemain sepak bola kelompok umur 12 tahun klub SSB Tunas Harapan Klampok Brebes, dilakukan terhadap 30 orang pemain yang dipilih menggunakan teknik purposive sampling dengan cara undian. Koordinasi diukur oleh tes koordinasi mata kaki, sedangkan pengukuran menendang didapat dari tes shooting. Penelitian ini mengatakan adanya hubungan yang signifikan antara koordinasi mata kaki dengan ketepatan menembak bola ke gawang sepak bola. Pernyataan itu didasarkan dari hasil penelitian 
dan hasil analisis regresi dan korelasi product moment yang telah dilakukan, dimana $r_{\text {hitung }}=$ $0,414>\mathrm{r}_{\text {tabel }} 5 \%=0,361$. Maka disimpulkan koordinasi mata kaki memiliki hubungan dengan ketepatan menembak bola (Adityatama, 2017).

Artikel ketiga yaitu penelitian "Kontribusi Kekuatan Otot Tungkai dan Koordinasi Mata Kaki Terhadap Akurasi Tendangan ke Gawang" yang dipublikasikan oleh Journal Sport Area Volume 4, Nomor 1, 2019 adalah penelitian yang ditulis oleh Sulastio and Zainur. Penelitian ini memiliki nilai S4 menurut Sinta (Science and Technology Index) dan memiliki nilai levels of internal validity dengan kategori B (limited) menurut metode critical appraisal. Penelitian ini ialah penelitian deskriptif korelasional yang salah satu tujuannya yaitu untuk mengetahui apakah terdapat kontribusi koordinasi mata kaki terhadap akurasi tendangan ke gawang (shooting) permainan sepak bola klub Belibis FC Kota Pekanbaru. Sampel penelitian ini seluruh pemain dengan jumlah 21 orang (total sampling). Tes shooting digunakan untuk mengukur menendang bola, sedangkan tes koordinasi mata kaki digunakan untuk mengukur koordinasi. Menurut analisis data yang telah dilakukan, untuk mencari kontribusi koordinasi mata kaki yaitu dengan menggunakan rumus product moment. Dengan konsekuensi perhitungan apabila nilai $\mathrm{r}_{\text {hitung }}=$ $r_{\text {tabel }}$ maka terdapat hubungan yang tidak signifikan antara koordinasi mata kaki dengan akurasi tendangan ke gawang, begitu juga sebaliknya. Berdasarkan hasil perhitungan didapatkan bahwa nilai $r_{\text {hitung }}=0,43$ dan nilai $\mathrm{r}_{\text {tabel }}=0,433$, dengan demikian nilai $\mathrm{r}_{\text {hitung }}>$ nilai $r_{\text {tabel }}$ yang artinya kedua variabel tersebut memiliki hubungan yang signifikan. Sehingga didapat kesimpulan bahwa terdapat kontribusi koordinasi mata kaki terhadap akurasi tendangan ke gawang, serta signifikan karena besar kontribusi koordinasi mata kaki terhadap akurasi tendangan yaitu sebesar $18,5 \%$ (Sulastio and Zainur, 2019).

Artikel keempat yang dijadikan sebagai sumber literatur utama oleh penulis yaitu penelitian "Hubungan Koordinasi Mata Kaki dengan Kemampuan Shooting dalam
Permainan Sepak Bola pada Klub Sepak Bola Himadirga Tahun 2013" yang dipublikasikan oleh Jurnal Ilmiah Mahasiswa Pendidikan Jasmani, Kesehatan dan Rekreasi, Volume 2, Nomor 3 : 235-244, Agustus 2016 adalah penelitian yang ditulis oleh Diwa. Penelitian ini memiliki nilai levels of internal validity dengan kategori B (limited) menurut metode critical appraisal. Metode penelitian yang digunakan yaitu desain deskriptif korelasional untuk mengetahui hubungan koordinasi mata kaki dengan kemampuan shooting dalam permainan sepak bola pada Klub Himadirga Unsyiah Tahun 2013. Sampel yang digunakan ialah seluruh pemain sebanyak 20 orang, disebut juga total sampling. Tes shooting dilakukan untuk mengukur kemampuan menendang bola, sedangkan untuk mengukur koordinasi menggunakan tes koordinasi mata kaki. Lalu didapatkan hasil yaitu melalui hipotesis yang telah diuji dengan ketertarikan yang baik antara satu dengan yang lainnya. Hasil penelitian tersebut menunjukkan bahwa terdapat hubungan yang positif dan signifikan antara koordinasi mata kaki dengan kemampuan shooting bola ditunjukkan dari hasil korelasi sebesar $(r=0,54)$ sehingga koordinasi mata kaki memberi hubungan sebesar 29,16\% dengan kemampuan shooting bola dan 70,84\% sisanya dipengaruhi oleh faktor-faktor yang lain (Diwa, 2016).

Artikel kelima yang ditemukan oleh penulis yaitu penelitian "Kontribusi Daya Ledak Otot Tungkai dan Koordinasi Mata Kaki Terhadap Akurasi Shooting Sepak Bola" yang dipublikasikan oleh Jurnal Patriot, Volume 1, Nomor 3, 2019 adalah penelitian yang ditulis oleh Cahyono and Sin. Penelitian ini memiliki nilai levels of internal validity dengan kategori B (limited) menurut metode critical appraisal. Penelitian ini adalah penelitian deskriptif korelasional yang salah satu tujuannya yaitu untuk melihat kontribusi mata kaki terhadap kemampuan akurasi shooting pemain Sekolah Sepak Bola Padang Canduah Kinali Kab. Pasaman Barat. Jumlah sampelnya ialah 30 orang pemain umur 15 dan 17 tahun. Teknik pengambilan sampelnya purposive sampling. Instrumen penelitiannya ialah tes koordinasi mata kaki untuk mengukur koordinasi dan tes 
shooting untuk mengukur keterampilan menendang bola. Berdasarkan hasil penelitian dan pengolahan data, diperoleh hasil terdapat kontribusi secara signifikan antara koordinasi mata kaki terhadap kemampuan akurasi shooting, dengan persentase sebesar $32,71 \%$. Selain itu dari uji signifikan koefisien kolerasi antara koordinasi mata kaki terhadap kemampuan akurasi shooting diperoleh hasil analisis statistik $t_{\text {hitung }} 3,6447>\mathrm{t}_{\text {total }} 1,7011$. Maka terdapat hubungan antara koordinasi mata kaki dan akurasi shooting (Cahyono and Sin, 2019).

Artikel keenam atau artikel terakhir yaitu penelitian "Hubungan Kekuatan Otot Tungkai dan Koordinasi Mata Kaki Terhadap Hasil Shooting Bola Diam ke Arah Gawang" yang dipublikasikan oleh Jurnal Ilmu Keolahragaan, Volume 2, Nomor 1, April 2019 adalah penelitian yang ditulis oleh Manurung. Penelitian ini memiliki nilai levels of internal validity dengan kategori B (limited) menurut metode critical appraisal. Penelitian ini yaitu penelitian deskriptif korelasional yang salah satu tujuannya yaitu untuk mengetahui hubungan koordinasi mata kaki terhadap hasil shooting bola diam ke arah gawang pada siswa ekstrakurikuler sepak bola di SMAN 8 Pontianak. Sampelnya adalah seluruh siswa ekstrakurikuler sepak bola di SMAN 8 Pontianak sebanyak 22 orang, disebut juga total sampling. Instumen penelitian yang digunakan adalah tes koordinasi mata kaki untuk mengukur koordinasi dan tes shooting untuk mengukur keterampilan menendang bola. Menurut hasil pengujian hipotesis, disimpulkan koordinasi mata kaki memiliki hubungan yang berarti terhadap hasil shooting bola diam ke arah gawang. Berdasarkan hasil analisis penelitian, sumbangan koordinasi mata kaki terhadap hasil shooting bola diam ke arah gawang sebesar $25,3 \%$, sedangkan sisanya sebesar 74,7\% dipengaruhi oleh variabel lain yang tidak dimasukkan dalam penelitian ini (Manurung, 2019).

Penulis menemukan bahwa enam artikel yang digunakan memiliki persamaan mengenai variabel yang dianalisis dalam penelitiannya. Semua artikel yang ditemukan memiliki variabel terikat yang sama, variabel tersebut adalah menendang bola. Sedangkan variabel bebas yang digunakan adalah koordinasi mata kaki. Namun terdapat perbedaan pada jumlah sampel yang digunakan pada tiap artikel. Sampel yang digunakan pada artikel 1 berjumlah 52 orang, artikel 2 berjumlah 30 orang, artikel 3 berjumlah 21 orang, artikel 4 berjumlah 20 orang, artikel 5 berjumlah 30 orang, dan artikel 6 berjumlah 22 orang.

Berdasarkan hasil analisis dari enam artikel tersebut, 5 artikel menyatakan bahwa terdapat hubungan antara koordinasi mata kaki dengan menendang bola, sedangkan 1 artikel menyatakan bahwa tidak adanya hubungan antara koordinasi mata kaki dengan menendang bola. Artikel tersebut adalah penelitian yang berjudul "A Study of Agility, Coordination and Speed as Related to Dribbling and Kicking Performance of Jimma, Woliso and Sebeta Town Male Football Players" yang ditulis oleh (Andualem. G., Silassie, \& Demena, 2016). Pada penelitian tersebut dikatakan bahwa saat melakukan tendangan, ada banyak keterbatasan yang menghambat kinerja pemain sepak bola. Hambatan pada penelitian ini yaitu faktor kebugaran fisik yang diteliti tidak dilakukan secara terpisah, faktor kebugaran fisik tersebut diantaranya yaitu kelincahan, koordinasi, dan kecepatan. Sehingga tenaga yang dihasilkan pemain sepak bola tidak maksimal dan mempengaruhi faktor kebugaran fisik satu sama lain. Jadi kemampuan olahraga atau aktivitas tertentu tergantung pada faktor kebugaran fisik terkait dengan keterampilannya. Jika koordinasi yang dimiliki pemain sepak bola baik dengan cara semakin dilatih terus-menerus, maka akan semakin baik juga keterampilan menendang bola yang dimiliki pemain sepak bola.

Menurut sumber artikel lain yang ditemukan penulis, menendang bola ialah teknik dasar penting dalam bermain sepak bola. Ini dikarenakan hampir keseluruhan dari permainan ini menggunakan tendangan, baik untuk menembakkan bola ke gawang musuh, operan pendek dan operan jauh. Untuk dapat menguasai teknik menendang bola, maka diperlukan penguasaan rangkaian gerakannya, sehingga dapat mengenai sasaran (Efendi, 2016). 
Manfaat menendang bola diantaranya untuk mengumpan bola ke teman satu grup, menembakkan banyak bola ke gawang musuh, dan menyapu untuk menggalakkan serangan musuh (Amin, 2018). Keterampilan menendang bola dapat memberikan manfaat jika seseorang melibatkan gerak tubuhnya dengan sengaja, yaitu untuk menghasilkan prestasi dengan menggunakan teknik, energi, dan juga waktu seefisien mungkin (Efendi, 2016).

Ketepatan menendang bola mempunyai tingkat kesulitan dan kerumitan yang tinggi karena mencakup salah satu unsurnya, yaitu unsur koordinasi mata kaki. Salah satu tujuan menendang bola yaitu menembakkan bola ke gawang musuh, ini merupakan teknik yang sering digunakan oleh setiap pemain sepak bola di tiap pertandingan. Koordinasi mata kaki ialah suatu hal penting dalam usaha mencetak prestasi yang maksimal bagi pemain sepak bola dalam latihan ketepatan menendang dengan cara menembakkan bola ke gawang musuh dengan sebanyak-banyaknya. Oleh karena itu, koordinasi mata kaki diperlukan pemain sepak bola saat melakukan tendangan. Semakin baik koordinasi mata kaki yang dimiliki, maka akan semakin baik juga ketepatan menendang bola tersebut dan dapat mencetak prestasi yaitu dengan cara menembakkan bola ke gawang lawan (Adityatama, 2017).

Koordinasi ialah proses kerja sama otot yang menghasilkan gerakan yang terarah dan tersusun dan bertujuan membentuk gerakan yang diperlukan dalam pelaksanaan suatu keterampilan teknik. Koordinasi mata kaki saat melakukan tendangan harus diperhatikan, sehingga perkenaan kaki dengan bola tepat dan arah bola menjadi tepat sasaran (Sulastio and Zainur, 2019). Selain itu, supaya dapat mencapai prestasi yang maksimal dalam permainan sepak bola maka dibutuhkan tenaga yang kuat, latihan yang teratur dan metode latihan yang berjalan sesuai dengan kepentingan pemain. Koordinasi mata kaki ialah hal paling utama dalam melakukan tembakkan bola ke gawang lawan (shooting), tanpa ada koordinasi yang baik maka shooting yang dilakukan menjadi tidak tepat sasaran.
Salah satu teknik dasar yang berperan penting dalam bermain sepak bola ialah menendang bola ke gawang (shooting). Teknik tersebut seperti terlihat mudah, tetapi sangat dibutuhkan konsentrasi yang tinggi agar shooting menjadi tepat sasaran. Dalam melakukan shooting yang bagus, dibutuhkan unsur kebugaran fisik yaitu koordinasi. Jika pemain sepak bola memiliki kondisi fisik yang baik maka dapat meningkatkan kemampuan sistem sirkulasi dan kerja jantung, peningkatan dalam kekuatan, koordinasi, kecepatan, kelentukan, stamina dan lainnya dari faktor kondisi fisik, respon atau tanggapan yang cepat dari organisme tubuh, serta pemulihan yang cepat dalam organ tubuh setelah latihan. Selain itu, jika kondisi fisik pemain baik maka ia akan lebih cepat dalam menguasai teknik gerakan yang dilatih. Koordinasi berhubungan dengan kemampuan untuk menggunakan rasa, yaitu penglihatan dan pendengaran, secara bersamasama dengan bagian tubuh tertentu dalam melakukan kegiatan motorik secara halus dan ketepatan yang tinggi. Secara psikologi, jika pemain memiliki kondisi fisik yang baik maka ia akan merasa lebih yakin dalam menghadapi pertandingan. Oleh karena itu, koordinasi memiliki peran penting dalam menendang bola (Diwa, 2016).

Koordinasi merupakan kombinasi beberapa kemampuan saat melakukan gerakan dengan tepat dan terkontrol sehingga dapat menghasilkan gerakan efisien dan efektif (Nugraheni and Widodo, 2017). Seseorang yang mempunyai koordinasi yang baik biasanya akan menampilkan gerakan yang baik dan tidak terlihat kaku. Koordinasi mata kaki sangat menentukan hasil dari akurasi tendangan ke gawang (shooting). Shooting merupakan usaha memindahkan bola ke sasaran dengan menggunakan kaki, untuk melakukan shooting bola ke gawang diperlukan koordinasi mata kaki. Untuk mendapatkan kemampuan akurasi shooting yang baik, koordinasi mata kaki perlu dilatih dan ditingkatkan melalui program latihan yang disusun secara sistematis (Cahyono and Sin, 2019).

Menurut (Ardiansyah, 2018), menendang bola merupakan teknik memindahkan bola dengan menggunakan kaki. Jauhnya tendangan 
dilakukan pada saat keadaan bola melayang di udara, diam, dan juga menggelinding. Menendang bola suatu ciri dominan dalam bermain sepak bola yang dipengaruhi oleh komponen fisik, salah satunya yaitu koordinasi. Koordinasi mata kaki berhubungan dengan kemampuan melakukan gerakan berdasarkan penglihatan dan juga gerak anggota tubuh bagian bawah, contohnya menendang bola. Oleh karena itu koordinasi mata kaki yang baik dapat menunjang gerakan menendang bola (Manurung, 2019).

Koordinasi mata kaki diperlukan karena koordinasi dapat mengontrol gerakan tubuh secara tepat. Fungsi mata untuk fokus melihat sasaran, sedangkan fungsi kaki sebagai media untuk melakukan tendangan. Indikator utama koordinasi yaitu gerak yang ekonomis dan ketepatan (Hartanto, Amrullah and Abdillah, 2016). Oleh sebab itu, koordinasi sangat dibutuhkan dalam bermain sepak bola, karena koordinasi merupakan faktor kebugaran fisik yang mempengaruhi teknik dasar, misalnya teknik menendang. Salah satu tujuan menendang ialah menembakkan bola ke gawang lawan (shooting). Saat melakukan shooting, koordinasi berperan penting, karena tanpa adanya koordinasi, maka akan sulit mengarahkan bola dengan tepat dan akurat ke arah gawang lawan. Sehingga koordinasi dapat menentukan keterampilan menendang bola setiap pemain. Jika pemain memiliki koordinasi yang baik, maka pemain pun akan dapat melakukan tendangan dengan baik sehingga dapat mencetak prestasi, begitupun sebaliknya.

Berdasarkan hasil analisis terhadap enam artikel yang ditemukan oleh penulis dan dijadikan sebagai sumber utama pada literature review ini serta beberapa artikel pendukung lain, penulis mengungkapkan bahwa koordinasi memiliki hubungan terhadap keterampilan menendang bola pada pemain sepak bola. Hal ini didukung dari hasil penelitian yang telah didapatkan pada tiap artikel.

\section{KESIMPULAN}

Berdasarkan enam artikel berupa jurnal penelitian yang telah dianalisis oleh penulis yang berkaitan dengan judul penulisan yaitu hubungan koordinasi terhadap keterampilan menendang bola pada pemain sepak bola, maka literature review ini memiliki kesimpulan bahwa terdapat hubungan koordinasi terhadap keterampilan menendang bola pada pemain sepak bola.

\section{DAFTAR PUSTAKA}

Adityatama, F 2017, 'Hubungan Power Otot Tungkai, Koordinasi Mata Kaki Dan Kekuatan Otot Perut Dengan Ketepatan Menembak Bola', JUARA: Jurnal Olahraga, 2(2), p. 82 . doi: 10.33222/juara.v2i2.37.

Amin, H. M 2018, 'Perbandingan Akurasi Long Pass Menggunakan Kaki Bagian Dalam, Kaki Bagian Luar dan Punggung Kaki Terhadap Siswa Ekstrakulikuler Sepakbola SMA Negeri 3 Kota Sukabumi Tahun 2018', Seminar Nasional Pendidikan Jasmani, 1(1), pp. 178-184.

Anam, K., Irawan, F. A. and Nurrachmad, L 2018, 'Pengaruh Metode Latihan dan Koordinasi Mata-Kaki terhadap Ketepatan Tendangan Jarak Jauh', Media Ilmu Keolahragaan Indonesia, 8(2), pp. 57-62. doi: 10.15294/miki.v8i2.17184.

Andualem. G., Silassie, \& Demena, T 2016, 'a Study of Agility, Coordination and Speed As Related To Dribbling and Kicking Performance of Jimma, Woliso and Sebeta Town Male Football Players Andualem', Journal of Physical Education Research, 3(I), pp. 47-55.

Ardiansyah 2018, 'BOLA PADA PERMAINAN SEPAKBOLA MURID SD INPRES'.

Cahyono, S. and Sin, T. H 2019, 'Kontribusi Daya Ledak Otot Tungkai dan Koordinasi Mata Kaki Terhadap Akurasi Shooting Sepakbola', pp. 299-305.

Diwa 2016, 'Hubungan Koordinasi Mata Kaki Dengan Kemampuan Shooting Dalam 
Permainan Sepak Bola Pada Klub Sepak Bola Himadirga Tahun 2013', 2(June), pp. 235-244.

Efendi, R 2016, 'Pengaruh Metode Latihan Practice Session, Test Session Dan Motivasi Berprestasi Terhadap Keterampilan Menendang Dalam Sepak Bola', Jurnal Pendidikan UNSIKA, 4(1), pp. 26-41.

Hartanto, D., Amrullah, R. and Abdillah, P. S 2016, 'Perbedaan Pengaruh Latihan Massed Practice, Distributed Practice, Dan Koordinasi Mata-Kaki Terhadap Kemampuan Passing Mendatar', Jurnal
Pendidikan Olahraga, 5(1), pp. 1-9.

Manurung, J. suman R 2019, 'Hubungan Kekuatan Otot Tungkai Dan Koordinasi Mata Kaki Terhadap Hasil Shooting Bola Diam Ke Arah Gawang', Jurnal Ilmu Keolahragaan, 2(1), p. 36. doi: 10.26418/jilo.v2i1.32630.

Nugraheni, W. and Widodo, A 2017, 'Wening Nugraheni; Dosen Prodi PJKR FKIP'.

Sulastio and Zainur 2019, 'Kontribusi Kekuatan Otot Tungkai Dan Koordinasi Mata Kaki Terhadap Akurasi Tendangan Ke Gawang', 4(1), pp. 278-284. 